\title{
Endoplasmic Reticulum-
} Mitochondria Crosstalk and Beta-
Cell Destruction in Type 1 Diabetes

\author{
Saurabh Vig ${ }^{1 \dagger}$, Joost M. Lambooij ${ }^{1,2 \dagger}$, Arnaud Zaldumbide ${ }^{1 * t}$ and Bruno Guigas ${ }^{2 * t}$ \\ 1 Department of Cell and Chemical Biology, Leiden University Medical Center, Leiden, Netherlands, ${ }^{2}$ Department of \\ Parasitology, Leiden University Medical Center, Leiden, Netherlands
}

\section{OPEN ACCESS}

Edited by: Eddie A. James, Benaroya Research Institute, United States

Reviewed by:

Michael A. Kalwat,

Indiana Biosciences Research

Institute, United States Jon D. Piganelli,

University of Pittsburgh, United States

*Correspondence: Bruno Guigas

b.g.a.guigas@/umc.n

Arnaud Zaldumbide

a.zaldumbide@/umc.n

'These authors have contributed equally to this work

Specialty section: This article was submitted to Autoimmune and Autoinflammatory Disorders, a section of the journal

Frontiers in Immunology

Received: 18 February 2021 Accepted: 29 March 2021 Published: 16 April 2021

Citation:

Vig S, Lambooij JM, Zaldumbide $A$ and Guigas B (2021) Endoplasmic Reticulum-Mitochondria Crosstalk and Beta-Cell Destruction in Type 1 Diabetes.

Front. Immunol. 12:669492. doi: 10.3389/fimmu.2021.669492
Beta-cell destruction in type 1 diabetes (T1D) results from the combined effect of inflammation and recurrent autoimmunity. In response to inflammatory signals, betacells engage adaptive mechanisms where the endoplasmic reticulum (ER) and mitochondria act in concert to restore cellular homeostasis. In the recent years it has become clear that this adaptive phase may trigger the development of autoimmunity by the generation of autoantigens recognized by autoreactive CD8 T cells. The participation of the ER stress and the unfolded protein response to the increased visibility of beta-cells to the immune system has been largely described. However, the role of the other cellular organelles, and in particular the mitochondria that are central mediator for beta-cell survival and function, remains poorly investigated. In this review we will dissect the crosstalk between the ER and mitochondria in the context of T1D, highlighting the key role played by this interaction in beta-cell dysfunctions and immune activation, especially through regulation of calcium homeostasis, oxidative stress and generation of mitochondrial-derived factors.

Keywords: endoplasmic reticulum, ER stress, mitochondria, Type 1 diabetes (T1D), beta-cell, inflammation, cytokines

\section{INTRODUCTION}

Type 1 diabetes (T1D) is an autoimmune disease that targets pancreatic beta-cells, leading to their progressive loss (1). For years, impaired thymic education or low affinity $\mathrm{T}$ cells were thought to be responsible of the immune attack directed against native self-proteins. However, accumulating evidence suggest that local inflammation or other forms of stress, like viral infection, toxic chemical exposure or dysglycemia, combined with genetic predisposition may lead to the generation and accumulation of aberrant or modified proteins to which central tolerance is lacking, thereby triggering autoimmunity (2-4).

The endoplasmic reticulum (ER), is the hub for protein synthesis, folding, modification and transport as well as for phospholipid and cholesterol biosynthesis (5). Alterations in ER homeostasis due to inflammatory stress, accumulation of misfolded proteins, and/or alterations in the cellular $\mathrm{Ca}^{2+}$ or redox balance triggers an unfolded protein response (UPR) through activation of ER transmembrane proteins [e.g. double-stranded RNA-activated protein kinase (PKR)-like ER kinase (PERK), inositol-requiring enzyme $1 \alpha$ (IRE1 $\alpha$ ) and activating transcription factor 6 (ATF6)]. These 
central mediators of the UPR sense the accumulation of misfolded proteins in the ER lumen and activate mechanisms to inhibit protein synthesis, restore expression of chaperones, like the $78-\mathrm{kDa}$ glucose regulated protein [also known as binding immunoglobulin protein] (GRP78/BiP), and initiate ER associated degradation pathway to eliminate newly synthesized proteins through proteasome-mediated degradation $(6,7)$. Persistent stimulation of the UPR in response to ER stress induces apoptosis via activation of $\mathrm{C} / \mathrm{EBP}$ homologous protein (CHOP), c-jun N-terminal kinase (JNK), death protein 5 (DP5) and other pro-apoptotic signals $(8,9)$. Several studies, have demonstrated that this adaptive phase disturbs (post)transcriptional, (post)-translational and degradation processes, increasing the complexity of the beta-cell proteome and peptidome, promoting the generation of neoantigens $(10,11)$.

Like the ER, mitochondria are complex and dynamic cellular organelles that play a key role in beta-cell functions, notably by coupling glucose metabolism to insulin secretion, but also in regulating apoptotic cell death via the production of reactive oxygen species (ROS) and release of cytochrome C $(12,13)$. In most eukaryotic cells, including beta-cells, mitochondria form dynamic networks that are continually reshaped by fission and fusion processes, under the control of specific mitochondrial membrane anchor proteins. Induction of the mitochondria UPR (UPRmt) plays an essential role in the maintenance of the mitochondrial integrity, dynamics and function in response to various stressors $(14,15)$. Currently, little is known regarding the impact of pro-inflammatory stimuli on mitochondrial dynamics/ bioenergetics and UPRmt in human beta-cells. Yet, the interaction between the ER and mitochondria during the adaptive mechanism to environmental stress indicates that both organelles orchestrate the communication between the beta-cells and the immune system. Therefore, further exploring the regulatory mechanisms involved in mitochondria-ER interaction and in particular those controlling $\mathrm{Ca}^{2+}$ homeostasis and mitochondrial homeostasis, is required for a better understanding of the pathophysiology of beta-cell failure and its immune-related consequences in T1D.

\section{ER-MITOCHONDRIA CROSSTALK IN BETA-CELL (DYS)FUNCTIONS}

The ER and mitochondria are organelles that physically interact in a highly dynamic and regulated manner, forming specific microdomains, termed mitochondria and ER contact sites (MERCs) or mitochondria-associated membranes (MAMs) when studied at the molecular level (16). It is well established that MAMs play a central role in cellular $\mathrm{Ca}^{2+}$ homeostasis (1719) and, more recently, they have also been shown to regulate mitochondrial dynamics and bioenergetics (20), ROS production (21), mitochondrial-mediated apoptosis (22), and inflammation $(22,23)$. MAMs are composed of membrane fractions from both the ER and the outer mitochondrial membrane (OMM) containing a large range of cell-specific molecular components involved in the tethering complex (16). Alterations in the MAMs composition and abnormal ER-mitochondria interaction have been reported to be associated with different pathological conditions, especially in type 2 diabetes (T2D) where organelle miscommunication has been suggested to underlie beta-cell inflammation, cell death and impaired metabolic function (24).

\section{ER-Mitochondria Tethering, $\mathrm{Ca}^{2+}$ Homeostasis and Beta-Cell Dysfunction}

The regulation of $\mathrm{Ca}^{2+}$ homeostasis is essential for proper betacell functions, because of its role in driving insulin granule biogenesis, trafficking and exocytosis but also by triggering multiple intracellular signaling pathways essential for the maintenance of beta-cell identity and survival (25). Cytosolic $\mathrm{Ca}^{2+}$ concentration is tightly controlled and results from a balance between its cellular influx and efflux, and its intracellular uptake and release by various organelles, such as ER, Golgi and the mitochondria, through specific exchangers, pumps, and channels (Figure 1). It is still unclear whether the mitochondria can play a significant role in directly buffering cytosolic $\mathrm{Ca}^{2+}$ in a quantitative manner under physiological conditions (26). However, acute and/or long-lasting modulation of inter-organelle communication, particularly under pathological conditions, may impact $\mathrm{Ca}^{2+}$ homeostasis in beta-cells. As such, channeling of the cation in between subcellular compartments, notably from the ER to the mitochondria, represents another way by which large quantities of $\mathrm{Ca}^{2+}$ can be conveyed and exert key regulatory roles on the organelle functions. Under homeostatic conditions, a transient increase in beta-cell mitochondrial matrix $\mathrm{Ca}^{2+}$ levels promotes ATP production by oxidative phosphorylation (OXPHOS). This occurs principally through direct activation of several tricarboxylic acid (TCA) cycle dehydrogenases and contributes to $\mathrm{K}_{\mathrm{ATP}}$ channel-mediated opening of L-type voltage-gated $\mathrm{Ca}^{2+}$ channels (L-VGCCs), increased cytosolic $\mathrm{Ca}^{2+}$ and sustained glucose-stimulated insulin secretion (GSIS) (27). However, any perturbations of this highly regulated spatiotemporal process would result in an altered mitochondrial homeostasis that may ultimately lead to bioenergetic dysfunction, enhanced oxidative stress and cell death. The ERmitochondrial connectivity was shown to involve a set of interacting proteins located in the MAMs (Figure 1, insert), allowing ER and mitochondria to share their content, especially $\mathrm{Ca}^{2+}$, through the $75-\mathrm{kDa}$ glucose-regulated protein (GRP75)mediated coupling of the ER inositol trisphosphate receptor (IP3R) with the mitochondrial voltage-dependent anionselective channel 1 (VDAC1) (28). The association formed by the ER vesicle-associated membrane protein-associated protein $B$ (VABP) with the OMM protein tyrosine phosphatase-interacting protein-51 (PTPIP51) could also contribute in the organelle interaction (29). Moreover, proteins involved in mitochondrial dynamics were also shown to be involved in this tethering, such as mitofusin 2 (MFN2) and mitochondrial fission 1 protein (FIS1). Indeed, FIS1 can directly interact with the ER B-cell receptor-associated protein 31 (Bap31), promoting $\mathrm{Ca}^{2+}$ transfer from ER to the mitochondria and subsequent induction of apoptosis (30). 


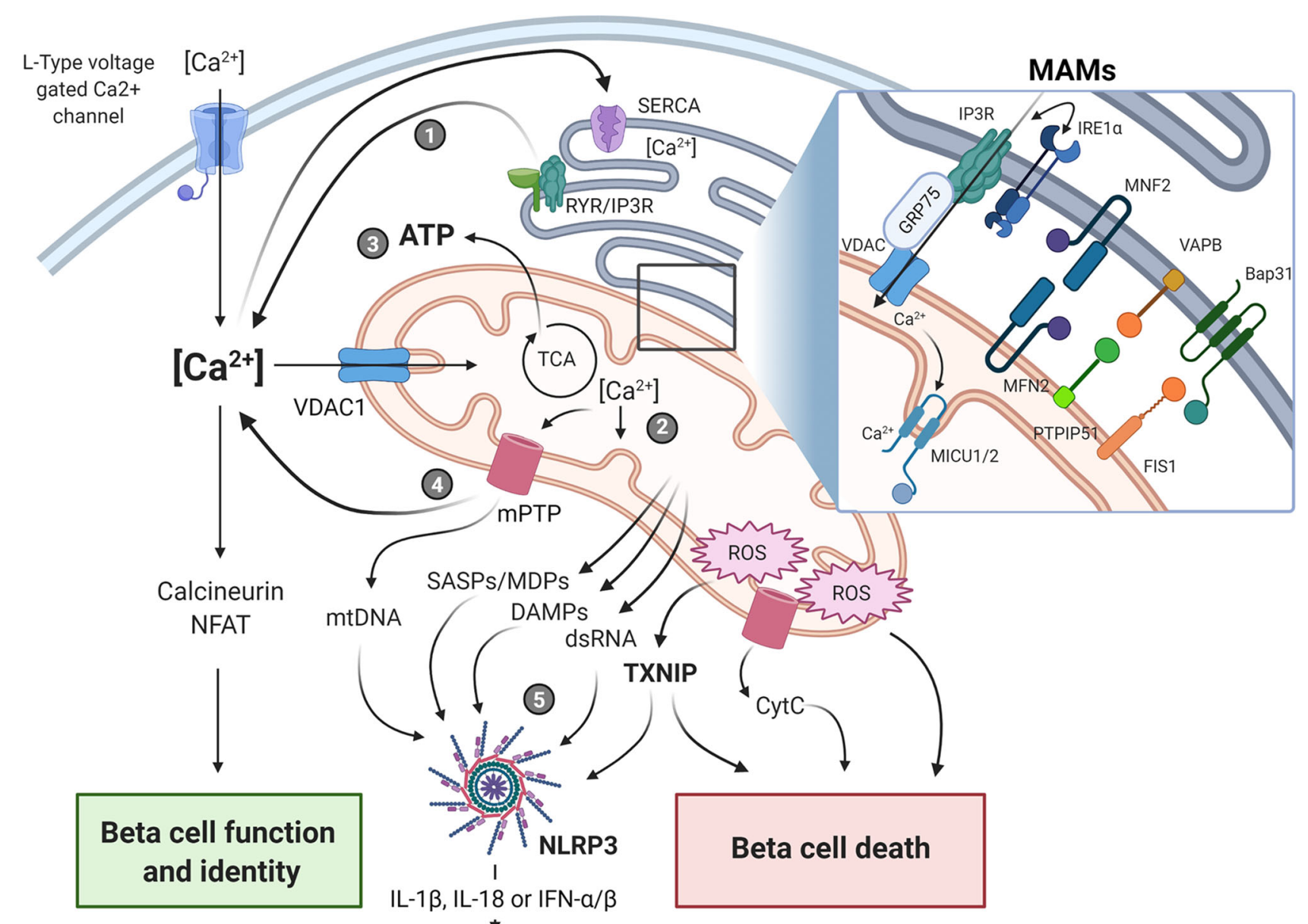

Chemokines / Cytokines release

FIGURE 1 | Endoplasmic reticulum-mitochondria crosstalk in beta-cell dysfunction and immune activation in type 1 diabetes. The crosstalk between the endoplasmic reticulum (ER) and the mitochondrial network is playing a central role in cellular $\mathrm{Ca}^{2+}$ homeostasis and beta-cell function. The physical ER-mitochondria interaction involves a set of proteins located in the mitochondrial-associated membranes (MAMs, insert) which allows the exchange of organelle respective content. Modulation of MAM assembly has been shown to regulate mitochondrial dynamics and bioenergetics, ROS production, and release of various mitochondrial-derived factors. Alterations of these highly regulated processes in response to $\mathrm{ER} /$ mitochondria stress, can contribute to beta-cell dysfunction and immunogenicity by triggering apoptotic beta-cell death and NLRP3 activation, ultimately promoting pro-inflammatory cytokine/chemokine production, immune cells recruitment within the islet microenvironment, and betacell destruction. Upon ER stress induction, the depletion of $\mathrm{ER} \mathrm{Ca}^{2+}$ store (1) induces mitochondrial $\mathrm{Ca}^{2+}$ accumulation (2). This increase in mitochondrial matrix $\mathrm{Ca}^{2+}$ concentration triggers oxidative phosphorylation and ATP production (3) in order to restore cellular and ER homeostasis. If this adaptive response fails to restore homeostasis, prolonged $\mathrm{Ca}^{2+}$ accumulation in the mitochondria would promote the opening of the MPTP, leading to increased mitochondrial membrane permeability and leakage of mitochondrial-derived factors, such as DAMPS, mtDNA, dsRNA (4) that ultimately activate downstream sensors/inflammasome (5). SASPs, senescenceassociated secretory phenotype; DAMPs, damage-associated molecular patterns; MDPs, mitochondrial-derived peptides; ROS, reactive oxygen species; mtDNA, mitochondrial DNA; mPTP, mitochondrial permeability transition pore; CytC, cytochrome C. The figure was created with BioRender.com.

Interestingly, it has recently been reported that besides its canonical function in UPR, IRE1 $\alpha$ also acts as a scaffold within the ER-mitochondria junction by directly interacting with IP3R, the main ER $\mathrm{Ca}^{2+}$ channel, ultimately affecting ER-mitochondria $\mathrm{Ca}^{2+}$ signaling (31). Indeed, the interaction between the respective C-terminal cytosolic domains of monomeric IRE1 $\alpha$ and IP3R proteins within the MAMs allows for a VDAC1mediated transfer of $\mathrm{Ca}^{2+}$ from the ER lumen to the mitochondrial matrix, leading to increased $\mathrm{Ca}^{2+}$ concentrations that trigger activation of TCA cycle and ATP production (31). Interestingly, it has been shown in pancreatic tissue sections that the number of IP3R-VDAC1 complexes assessed by in situ proximity ligation assay was significantly lower in beta-cells from individuals with $\mathrm{T} 2 \mathrm{D}$ as compared to non-diabetic controls, suggesting that alterations in the ER-mitochondria interaction may contribute to beta-cell dysfunction under 
diabetic conditions (32). Furthermore, induction of ER stress by treatment with the long-chain fatty acid palmitate significantly reduced ER-mitochondria interactions and altered GSIS in the murine Min6-B1 beta-cell line (32). More recently, the same team has also reported that both acute or prolonged exposure to glucose may promote ER-mitochondria interactions while having opposite impact on mitochondrial $\mathrm{Ca}^{2+}$ homeostasis and beta-cell insulin secretion (33). Indeed, it was shown that an acute glucose challenge enhanced MAMs assembly, as evidenced by increased VDAC1-IP3R2 proximity, which was associated with higher ATP-stimulated ER-mitochondrial $\mathrm{Ca}^{2+}$ transfer, intramitochondrial $\mathrm{Ca}^{2+}$ accumulation and GSIS in rat INS-1E beta-cell line. This ER-mitochondria interaction was abolished when MAM tethering protein GRP75 was knocked down by siRNA, demonstrating that organelle coupling is crucial for beta-cell $\mathrm{Ca}^{2+}$ homeostasis and insulin exocytosis under homeostatic conditions (33). Counterintuitively, extending the duration of glucose exposure to mimic diabetogenic conditions also resulted in increased MAM formation in both INS-1E cells and human pancreatic islets. However, despite higher organelle interactions, chronic glucose exposure triggered ER stress and disruption of ER-mitochondrial $\mathrm{Ca}^{2+}$ exchange, characterized by a progressive depletion of the ER $\mathrm{Ca}^{2+}$ store and increased $\mathrm{Ca}^{2+}$ levels in fragmented mitochondria, ultimately leading to altered mitochondrial respiration and impaired GSIS (33). Remarkably, this feature also resembles the effect of pro-inflammatory cytokines in the context of T1D, with $\mathrm{Ca}^{2+}$ depletion in the ER being associated with enhanced protein misfolding, UPR activation, and beta-cell death (34). Of note, treatment with the ER stress inducer tunicamycin also increased VDAC1-IP3R2 interactions in INS-1E cells, suggesting that increased organelle tethering could constitute an adaptive mechanism for restoring ER-mitochondria $\mathrm{Ca}^{2+}$ homeostasis (33). Whether beta-cell ER stress and IRE $1 \alpha$-mediated UPR associated with islet inflammation in T1D would be the cause or the consequence of impaired MAM assembly that leads to altered mitochondrial $\mathrm{Ca}^{2+}$ homeostasis and mitochondria-mediated immune activation, remains however to be investigated.

\section{ER-Mitochondria Crosstalk, Oxidative Stress and Beta-Cell Death}

MAMs have also been identified as a critical hub in the regulation of beta-cell death, because ER stress and alterations in mitochondrial $\mathrm{Ca}^{2+}$ homeostasis are linked to increased local ROS production and induction of intrinsic apoptotic pathways $(35,36)$. IRE1 $\alpha$ was shown to be involved in the regulation of the OMM B cell lymphoma-2 (Bcl-2) protein family. Once activated, IRE1 $\alpha$ can bind the TNF receptor associated factor 2 (TRAF2) adaptor and activate the JNK signaling pathway, triggering apoptosis via upregulation of $\mathrm{CHOP}$ and downregulation of the anti-apoptotic protein $\mathrm{Bcl}-2$ (10). Additionally, CHOP promotes Bcl-2 phosphorylation which impairs its inhibitory interaction with the pro-apoptotic proteins, $\mathrm{Bcl}-2$ associated $\mathrm{X}$ protein (Bax) and Bcl-2 homologous antagonist killer protein (Bak). These proteins induce IP3R-mediated cytosolic release of $\mathrm{Ca}^{2+}$ from the ER which is next channeled into the mitochondria through
$\operatorname{VDAC1}(37,38)$. This causes an increase in mitochondrial matrix $\mathrm{Ca}^{2+}$ concentration that triggers the opening of the mitochondrial permeability transition pore (mPTP), a non-specific channel located in the inner mitochondrial membrane (IMM), ultimately leading to cytochrome C-mediated activation of apoptotic pathway and cell death $(39,40)$. In addition to IRE1 $\alpha$, the other ER stress-driven UPR arms, involving PERK and ATF6, can also participate in MAM assembly and ER-mitochondria crosstalk. Indeed, ATF6 has been shown to promote mitochondrial biogenesis through interaction with peroxisome proliferatoractivated receptor gamma coactivator $1 \alpha$ (PGC-1 $\alpha)(41,42)$, an effect that would presumably promote mitochondrial network remodeling and impact the ER-mitochondria interaction. PERK has also been reported to be located in the MAMs fraction and involved in mediating ER-mitochondria interaction during ROS-induced oxidative stress (43). Moreover, ATF4, located downstream of PERK, has been shown to regulate mitochondrial dynamics by controlling the expression of the ubiquitin ligase Parkin, that is responsible for the removal of the damaged mitochondria by mitophagy during ER stress (44). Interestingly, Parkin also mediates ER-mitochondria crosstalk during ER stress by increasing MAM microdomains assembly for maintaining intra-organelle $\mathrm{Ca}^{2+}$ transfer (45). In addition, ATF4 can participate to the regulation of the oxidative stress response and apoptosis in beta-cells through interaction with the transcription factor nuclear factor erythroid 2-related factor 2 (NRF2) (46-48). In fact, under inflammatory conditions, the increase in oxidative stress may lead to oxidation of cysteine residues on Kelch-like ECH associated protein 1 (KEAP1), leading to conformational changes and disruption of its interaction with NRF2. Next, NRF2 can translocate to the nucleus where it exerts a dual function. On one hand, it can form a heterodimer with ATF4 and regulate antioxidant genes (heme oxygenase-1, NAD $(\mathrm{P}) \mathrm{H}$ : quinone oxidoreductase, glutathione S-transferase) and prevent cell death by activating anti-apoptotic genes (B-cell lymphomaextra large (Bcl-xL), Bcl-2). On the other hand, it can also compete with ATF4 and inhibit its binding to the Amino Acid Responsive Element (AARE) on the CHOP promoter, ultimately limiting cytochrome C release and apoptosis (49).

Mitochondria form a very dynamic and plastic network that is continuously re-organized owing to tightly regulated processes involving fission, fusion and mitophagy-mediated clearance of dysfunctional organelles. On one hand, mitochondrial network remodeling, especially in beta-cell, is important for organelle bioenergetics and functions, including OXPHOS-driven ATP synthesis, $\mathrm{Ca}^{2+}$ signaling and cell survival. On the other hand, mitochondrial dynamics and their interaction with other subcellular structures are also regulated through intrinsic organelle metabolic activity and ROS production, with disrupted OXPHOS and increased oxidative stress promoting mitochondrial fission and mitophagy (50). In beta-cells, changes in the expression of mitochondrial fission/fusion proteins in response to both inflammatory and metabolic stresses have been shown to affect mitochondrial dynamic and ultrastructure, leading to impaired organelle energetics and altered beta-cell GSIS and survival (51). For instance, prolonged exposure to high 
glucose and/or lipotoxic environment increases the expression of the fission protein dynamin-related protein 1 (DRP1), reduces GSIS, and increases apoptotic cell death in INS-1E cells $(52,53)$. Similarly, DRP1 expression was found to be increased in betacells from dysfunctional pancreatic islets in a model of hyperglycemic T2D mice (54). In line with this, overexpression of DRP1 or FIS1 in various in vitro models of murine beta-cells was generally associated with increased mitochondrial fission, impaired mitochondrial bioenergetics and increased apoptosis (Table S1). More recently, the expression of the orphan nuclear receptor Nor1/Nr4a3, which was previously identified as a negative regulator of beta-cell mass (55), was found to be increased by proinflammatory cytokines and involved in betacell mitochondrial dysfunction (56). Indeed, following mitochondrial translocation, Nor1 promotes the disruption of mitochondrial network, leading to reduction in glucose oxidation and ATP production that ultimately contribute to apoptotic beta-cell death (56). By contrast, a balanced expression of the fission protein FIS1 was shown to be required for maintenance of mitochondrial network remodeling, beta-cell survival and efficient GSIS in INS-1 cells (57). Interestingly, dampening high glucose/lipid-induced beta-cell stress restores mitochondrial dynamics by increasing fusion and reducing fission, leading to decreased apoptosis in mouse islets (58).

\section{FROM MITOCHONDRIA DYSFUNCTION TO BETA-CELL IMMUNOGENICITY?}

The prokaryotic origin of mitochondria positions the organelle as a potential source of intracellular mediators that can trigger innate immunity through release of various damage-associated molecular patterns (DAMPS) and/or pathogen-associated molecular patterns (PAMPS). Among these mitochondrialderived molecules, specific phospholipids from the OMM (59), $\mathrm{N}$-formyl methionine containing peptides which are legacy from prokaryotic translation initiation phase (60), and also mitochondrial DNA (mtDNA) containing hypomethylated CpG motifs that closely resemble bacterial CpG DNA can all trigger downstream immune activation, either directly or via pattern recognition receptor (PRRs)-mediated activation of the inflammasome.

In response to environmental stresses that lead to altered mitochondrial homeostasis, the organelle integrity is maintained, like in the ER, by chaperones (HSP60, HSP70) and proteases (ClpXP, ATP-dependent AAA protease LON) that control protein synthesis, folding and degradation and activate antioxidant mechanisms for ROS detoxification (61). Interestingly, the humoral and $\mathrm{T}$ cell reactivity against both HSP60 and HSP70 reported in newly diagnosed T1D patients may illustrate the important role played by mitochondrial dysfunction and stress in triggering autoimmunity $(62,63)$. During ER and/or mitochondrial stress, disruption in the $\mathrm{Ca}^{2+}$ homeostasis opens the $\mathrm{mPTP}$ which may lead to cytoplasmic release of mtDNA or mitochondrial double-stranded RNA (dsRNA) from mitochondria and induction of a programmed cell death. In line with this observation, it has been shown that activation of Bax/Bak during apoptosis led to the formation of a macropores on the OMM which allows the IMM to swell out into the cytosol and release mitochondrial factors, including mtDNA and dsRNA, without caspases activation (64). Classically, the presence of cytosolic mtDNA is sensed by cyclic GMP-AMP synthase (cGAS), resulting in stimulator of interferon genes (STING) activation and downstream phosphorylation of tyrosine kinase non receptor 1 (TNK1) and interferon regulatory factor 3 (IRF3), ultimately leading to increased transcription of type 1 IFN genes (65). Alternative pathways can trigger TLR9 activation within endosomes, leading to NFKBmediated inflammasome (NLRP1 and NLRP3) activation, increased caspase 1 activity and subsequent IL-1 $\beta$ and IL-18 processing (66). Although little is known on the beta-cell inflammasome, studies conducted in both INS-1E cells and human islets have shown that prototypical inflammatory cytokines of the insulitis microenvironment may differentially regulate NLRP1 and NLRP3 via ATF4 and NFKB pathways (67). Similarly, cytosolic accumulation of dsRNA, generated after bidirectional transcription of circular mtDNA, can be detected by several cellular sensors, including protein kinase $R$ (PKR), retinoic acid-inducible gene I (RIG-I) and melanoma differentiation-associated protein 5 (MDA5), to inhibit protein synthesis via phosphorylation of the eIF2 $\alpha$, recruitment of TANK-binding kinase-1, inducible I $\mathrm{I} B$ kinase (IKKe), and activation of IFN regulatory factor 3 and 7 and $\mathrm{NFKB}$, to promote type I IFN secretion (68). Altogether, these findings highlight a potential mechanism by which ER stress-induced release of mitochondrial genomic material might lead to the activation of inflammatory pathways in beta-cells, contributing to their eventual demise.

The production of IL- $1 \beta$, IL-18 or IFN- $\alpha / \beta$ by islet resident innate immune cells and/or endocrine cells (69-73), among which beta-cell is probably not the major source, facilitates the recruitment of immune cells [e.g. monocytes/macrophages, dendritic cells (DC)] to the inflammatory microenvironment within pancreas where they might contribute to the priming and activation of adaptive immune cells (74). Type I IFNs signature has been highly associated with disease development and progression from prediabetic stage (75). Moreover, among the 50 loci linked to T1D, several are expressed in beta-cells and involved in innate immunity [e.g. Protein Tyrosine Phosphatase, Non-Receptor Type 2 (PTPN2), Tyrosine Kinase 2 (TYK2), Interferon Induced Helicase C Domain 1 (IFIH1) and BTB Domain and CNC Homolog 2 (BACH2)]. In addition, a recent meta-analysis comparing RNAseq data from tissues of patients with T1D (beta-cells), systemic lupus erythematosus (SLE, kidney cells), multiple sclerosis (MS, optic chiasm) and rheumatoid arthritis (RA, joint tissue), identified a type I IFN signature as a common feature, further highlighting a more global role of type I IFN signaling in the development of autoimmune disease (76).

Although it is tempting to speculate that mitochondria permeability and subsequent genetic material leakage may participate to immune activation by beta-cells, strong 
supportive data are currently lacking to clearly implicate these processes in T1D development. However, a recent study has reported that inhibition of VDAC1 oligomerization during mitochondrial stress reduced accumulation of cytosolic mtDNA, expression of type I IFN genes, and circulating auto antibody levels in a mouse model of SLE, highlighting the possible role of cytosolic mtDNA in triggering autoimmunity (77). Furthermore, a relation between mitochondria content and beta-cell autoimmune destruction in T1D has also been suggested by the identification of a SNP located within the mitochondrial gene for $\mathrm{NADH}$ dehydrogenase $2(m t-\mathrm{Nd} 2)$ that was associated with T1D (78). In this study, the presence of the $m t-N d 2 a$ (resistant) allele prevented both T1D after adoptive transfer of diabetogenic CD4+ T cell clones in NOD mice and beta-cell destruction by CD8 $\mathrm{T}$ cells in vitro (78). In addition, depletion of mtDNA from $\beta$ lox 5 cells lowered cytokinemediated destruction and prevented CD8 T cell-mediated cytotoxic killing (79), positioning mtDNA a potentially important trigger of beta-cell destruction.

Alterations in intracellular $\mathrm{Ca}^{2+}$ homeostasis by ER/ mitochondria stress may also have broad consequences on the cell visibility to the immune system by generating neoantigens, through regulation of mRNA splicing and protein synthesis or proteasomal degradation (80-82). Several studies have indeed highlighted the role of $\mathrm{Ca}^{2+}$ as activator for post translational enzymes transglutaminase 2 (TG2) and protein arginine deiminases (PADs) involved in deamidation and citrullination, respectively. These enzymes are mainly involved in coeliac disease and RA but have also been extensively studied in the context of T1D as important component of beta-cell-directed autoimmunity $(3,83,84)$. In these processes, ROS participates in the regulation of post-translation modification (PTM) enzymes, inhibiting TG2 ubiquitination in endothelial cells or controlling activity of PAD4 $(85,86)$. Deamidation of glutamine and asparagine residues in the insulin $B$ chain modifies the structural properties of insulin-derived epitopes and generates perfect anchors for peptide presentation in HLA-DQ2/-DQ8 predisposing haplotype (87). Similarly, citrullination has been shown to turn the GRP78/BiP ER chaperone into an important autoantigen in T1D by an ER stress-independent mechanism involving alteration of $\mathrm{Ca}^{2+}$ homeostasis and activation of PADs (84). In addition, changes in cytosolic $\mathrm{Ca}^{2+}$ level activate nuclear factor of activated $\mathrm{T}$ cells (NFAT) via the calcineurin/calmodulin pathway which plays a critical role in beta-cell proliferation and maintenance of beta-cell mass and function. As such, immunosuppressive drugs used in islet transplantation, such as cyclosporin A or FK506, inhibit calcineurin pathway, impair beta-cell function and trigger the development of post-transplantation diabetes mellitus (New Onset Diabetes After Transplantation [NODAT]) (88). Of note, new calcineurin inhibitors, such as voclosporin, has been recently reported to have less deleterious effects on islet functions (89). Increased cytosolic $\mathrm{Ca}^{2+}$ also promotes phospholipase $\mathrm{C}$ activation and production of IP3, which stimulates $\mathrm{Ca}^{2+}$ mobilization and subsequent activation of protein kinase $\mathrm{C}$ (PKC) and downstream MAP kinases (JNK and ERK) that ultimately leads to activation of $\mathrm{NF \kappa B}$-dependent transcriptional program and increased expression of the chemokines IL8, CCL2, CXCL10 and CXCL12 (25). Although $\mathrm{Ca}^{2+}$ chelation had serious deleterious effect on beta-cell function and GSIS in vitro, it prevented DC migration to insulinoma (90) and PAD enzymes activation (4), highlighting its role as a cellular mediator in the communication with the immune compartment. This also suggests that restoration of intracellular $\mathrm{Ca}^{2+}$ homeostasis may inhibit immune cell trafficking to the pancreatic islets and reduce beta-cell immunogenicity. Interestingly, chemical inhibition of the NFKB pathway reduced IL-8 production by stressed human betacells and prevented neutrophil migration, an effect mediated by the proton exchanger GRP68 and the transcription factor RFX6 which are also involved in the regulation of $\mathrm{Ca}^{2+}$ homeostasis (91).

Another consequence of ER stress and mitochondria dysfunction is the induction of cell senescence (92), secondary to increased ROS production and impaired redox status $(21,93$, 94). Cellular senescence is a complex cell fate response that is characterized by the release of senescence-associated secretory phenotypes (SASPs) in response to multiple types of endogenous and exogenous stressors. The SASP components are of diverse nature, including cytokines and chemokines but also a large range of soluble and insoluble factors, and can contribute to immune activation, by promoting infiltration of immune cells. Although further studies are definitely required, it has been recently reported that islets from T1D mice as well as betacells from T1D donors display increased markers of senescence during disease progression (95), suggesting that beta-cell senescence may be an adaptive response to prolonged cellular stress that can contribute to autoimmunity through SASPs (96). Interestingly, studies aiming at eliminating senescent beta-cells by using specific senolytic drugs show remarkable results in limiting T1D progression in mice models $(95,97)$. These effects were associated with reduction in insulitis and improvements of both glucose metabolism and beta-cell function $(95,97)$. In response to metabolic activation and stress-associated UPRmt, mitochondria can also secrete mitochondria-derived peptides (MDPs), which are small bioactive peptides encoded by mtDNA that are mainly acting as retrograde signals to regulate mitochondrial energetics $(98,99)$. Although supporting data are currently sparse, especially in beta-cells, one can speculate that alterations in MDPs by inflammatory microenvironment may also contribute to modulate the cell communication with the immune compartment through various signaling pathways.

\section{CONCLUSION}

Dysfunctional mitochondria has been particularly studied in the context of metabolic disorders and T2D, where it has been associated for decades to insulin resistance and beta-cell failure. Although the beta-cell failure in pancreatic islets differs in many aspect between T1D and T2D [for review (100)], the presence of an islet-specific inflammatory microenvironment characterized by elevated local concentrations of type 1 cytokines $(67,101)$, together with enhanced recruitment and/ or activation of tissue-resident innate and adaptive immune cells 
(e.g. macrophages, B cells and T cells) (102) and accumulation of amyloid deposit $(103,104)$ represent common features to both pathologies. Consequently, the possibility of repurposing T2D drugs for $\mathrm{T} 1 \mathrm{D}$, to improve blood glucose management for relapsing metabolic and oxidative stress on beta-cells and limiting further immune destruction is worth considering. Ongoing studies using metformin, GLP-1 analogues, SGLT-2 inhibitors, or the L-VGCC inhibitor verapamil, which are either modulating mitochondrial bioenergetics/ROS/mPTP [metformin; (105-108)], ER stress [GLP-1 analogues; (109, 110)], glucose toxicity [SGLT-2 inhibitors; $(111,112)$ ] or cellular $\mathrm{Ca}^{2+}$ homeostasis [verapamil; $(113,114)$ ] are currently explored in the framework of clinical trials. These conceptually attractive novel approaches would also require further supportive mechanistic in vitro molecular studies in human primary beta-cells/islets and/or relevant beta-cell line models.

\section{AUTHOR CONTRIBUTIONS}

All the authors contributed equally to the review. SV and JL wrote the first draft of the manuscript. BG and AZ edited and

\section{REFERENCES}

1. Ilonen J, Lempainen J, Veijola R. The heterogeneous pathogenesis of type 1 diabetes mellitus. Nat Rev Endocrinol (2019) 15:635-50. doi: 10.1038/ s41574-019-0254-y

2. Kracht MJL, Zaldumbide A, Roep BO. Neoantigens and Microenvironment in Type 1 Diabetes: Lessons from Antitumor Immunity. Trends Endocrinol Metab (2016) 27:353-62. doi: 10.1016/j.tem.2016.03.013

3. Roep BO, Kracht MJ, van Lummel M, Zaldumbide A. A roadmap of the generation of neoantigens as targets of the immune system in type 1 diabetes. Curr Opin Immunol (2016) 43:67-73. doi: 10.1016/ j.coi.2016.09.007

4. Marre ML, Piganelli JD. Environmental Factors Contribute to beta Cell Endoplasmic Reticulum Stress and Neo-Antigen Formation in Type 1 Diabetes. Front Endocrinol (Lausanne) (2017) 8:262. doi: 10.3389/ fendo.2017.00262

5. Schwarz DS, Blower MD. The endoplasmic reticulum: structure, function and response to cellular signaling. Cell Mol Life Sci (2016) 73:79-94. doi: 10.1007/s00018-015-2052-6

6. Fonseca SG, Gromada J, Urano F. Endoplasmic reticulum stress and pancreatic beta-cell death. Trends Endocrinol Metab (2011) 22:266-74. doi: 10.1016/j.tem.2011.02.008

7. Walter P, Ron D. The unfolded protein response: from stress pathway to homeostatic regulation. Science (2011) 334:1081-6. doi: 10.1126/science. 1209038

8. Gurzov EN, Ortis F, Cunha DA, Gosset G, Li M, Cardozo AK, et al. Signaling by IL-1beta+IFN-gamma and ER stress converge on DP5/Hrk activation: a novel mechanism for pancreatic beta-cell apoptosis. Cell Death Differ (2009) 16:1539-50. doi: 10.1038/cdd.2009.99

9. Nakayasu ES, Qian WJ, Evans-Molina C, Mirmira RG, Eizirik DL, Metz TO. The role of proteomics in assessing beta-cell dysfunction and death in type 1 diabetes. Expert Rev Proteomics (2019) 16:569-82. doi: 10.1080/ 14789450.2019.1634548

10. Eizirik DL, Cardozo AK, Cnop M. The role for endoplasmic reticulum stress in diabetes mellitus. Endocr Rev (2008) 29:42-61. doi: 10.1210/er.2007-0015

11. Thomaidou S, Zaldumbide A, Roep BO. Islet stress, degradation and autoimmunity. Diabetes Obes Metab (2018) 20 Suppl 2:88-94. doi: 10.1111/dom.13387 wrote sections of the manuscript. AZ designed the figure. All authors contributed to the article and approved the submitted version.

\section{FUNDING}

This work is supported by DON Foundation and the Dutch Diabetes Research Foundation, JDRF and by IMI2-JU under grant agreement No 115797 (INNODIA) and No 945268 (INNODIA HARVEST). This Joint Undertaking receives support from the Union's Horizon 2020 research and innovation program and "EFPIA", "JDRF" and "The Leona M. and Harry B. Helmsley Charitable Trust".

\section{SUPPLEMENTARY MATERIAL}

The Supplementary Material for this article can be found online at: https://www.frontiersin.org/articles/10.3389/fimmu.2021. 669492/full\#supplementary-material

12. Chen J, Stimpson SE, Fernandez-Bueno GA, Mathews CE. Mitochondrial Reactive Oxygen Species and Type 1 Diabetes. Antioxid Redox Signal (2018) 29:1361-72. doi: 10.1089/ars.2017.7346

13. Las G, Oliveira MF, Shirihai OS. Emerging roles of beta-cell mitochondria in type-2-diabetes. Mol Aspects Med (2020) 71:100843. doi: 10.1016/ j.mam.2019.100843

14. Qureshi MA, Haynes CM, Pellegrino MW. The mitochondrial unfolded protein response: Signaling from the powerhouse. J Biol Chem (2017) 292:13500-6. doi: 10.1074/jbc.R117.791061

15. Naresh NU, Haynes CM. Signaling and Regulation of the Mitochondrial Unfolded Protein Response. Cold Spring Harb Perspect Biol (2019) 11:1-17. doi: $10.1101 /$ cshperspect.a033944

16. Herrera-Cruz MS, Simmen T. Over Six Decades of Discovery and Characterization of the Architecture at Mitochondria-Associated Membranes (MAMs). Adv Exp Med Biol (2017) 997:13-31. doi: 10.1007/ 978-981-10-4567-7 2

17. Kerkhofs M, Bittremieux M, Morciano G, Giorgi C, Pinton P, Parys JB, et al. Emerging molecular mechanisms in chemotherapy: $\mathrm{Ca}(2+)$ signaling at the mitochondria-associated endoplasmic reticulum membranes. Cell Death Dis (2018) 9:334. doi: 10.1038/s41419-017-0179-0

18. Marchi S, Bittremieux M, Missiroli S, Morganti C, Patergnani S, Sbano L, et al. Endoplasmic Reticulum-Mitochondria Communication Through Ca (2+) Signaling: The Importance of Mitochondria-Associated Membranes (MAMs). Adv Exp Med Biol (2017) 997:49-67. doi: 10.1007/978-981-104567-7_4

19. Romero-Garcia S, Prado-Garcia H. Mitochondrial calcium: Transport and modulation of cellular processes in homeostasis and cancer (Review). Int J Oncol (2019) 54:1155-67. doi: 10.3892/ijo.2019.4696

20. Tagaya M, Arasaki K. Regulation of Mitochondrial Dynamics and Autophagy by the Mitochondria-Associated Membrane. Adv Exp Med Biol (2017) 997:33-47. doi: 10.1007/978-981-10-4567-7_3

21. Janikiewicz J, Szymanski J, Malinska D, Patalas-Krawczyk P, Michalska B, Duszynski J, et al. Mitochondria-associated membranes in aging and senescence: structure, function, and dynamics. Cell Death Dis (2018) 9:332. doi: 10.1038/s41419-017-0105-5

22. Missiroli S, Patergnani S, Caroccia N, Pedriali G, Perrone M, Previati M, et al. Mitochondria-associated membranes (MAMs) and inflammation. Cell Death Dis (2018) 9:329. doi: 10.1038/s41419-017-0027-2 
23. Martinvalet $\mathrm{D}$. The role of the mitochondria and the endoplasmic reticulum contact sites in the development of the immune responses. Cell Death Dis (2018) 9:336. doi: 10.1038/s41419-017-0237-7

24. Rieusset J. The role of endoplasmic reticulum-mitochondria contact sites in the control of glucose homeostasis: an update. Cell Death Dis (2018) 9:388. doi: 10.1038/s41419-018-0416-1

25. Sabatini PV, Speckmann T, Lynn FC. Friend and foe: beta-cell $\mathrm{Ca}(2+)$ signaling and the development of diabetes. Mol Metab (2019) 21:1-12. doi: 10.1016/j.molmet.2018.12.007

26. Williams GS, Boyman L, Chikando AC, Khairallah RJ, Lederer WJ. Mitochondrial calcium uptake. Proc Natl Acad Sci USA (2013) 110:1047986. doi: $10.1073 /$ pnas. 1300410110

27. Jung SR, Reed BJ, Sweet IR. A highly energetic process couples calcium influx through L-type calcium channels to insulin secretion in pancreatic beta-cells. Am J Physiol Endocrinol Metab (2009) 297:E717-27. doi: 10.1152/ ajpendo.00282.2009

28. Szabadkai G, Bianchi K, Varnai P, De Stefani D, Wieckowski MR, Cavagna D, et al. Chaperone-mediated coupling of endoplasmic reticulum and mitochondrial Ca2+ channels. J Cell Biol (2006) 175:901-11. doi: 10.1083/jcb.200608073

29. De Vos KJ, Morotz GM, Stoica R, Tudor EL, Lau KF, Ackerley S, et al. VAPB interacts with the mitochondrial protein PTPIP51 to regulate calcium homeostasis. Hum Mol Genet (2012) 21:1299-311. doi: 10.1093/hmg/ddr559

30. Iwasawa R, Mahul-Mellier AL, Datler C, Pazarentzos E, Grimm S. Fis1 and Bap31 bridge the mitochondria-ER interface to establish a platform for apoptosis induction. EMBO J (2011) 30:556-68. doi: 10.1038/emboj.2010.346

31. Carreras-Sureda A, Jana F, Urra H, Durand S, Mortenson DE, Sagredo A, et al. Non-canonical function of IRE1 alpha determines mitochondriaassociated endoplasmic reticulum composition to control calcium transfer and bioenergetics (vol 21, pg 755, 2019). Nat Cell Biol (2019) 21:913-3. doi: 10.1038/s41556-019-0355-9

32. Thivolet C, Vial G, Cassel R, Rieusset J, Madec AM. Reduction of endoplasmic reticulum- mitochondria interactions in beta cells from patients with type 2 diabetes. PloS One (2017) 12:e0182027. doi: 10.1371/journal.pone.0182027

33. Dingreville F, Panthu B, Thivolet C, Ducreux S, Gouriou Y, Pesenti S, et al. Differential Effect of Glucose on ER-Mitochondria $\mathrm{Ca}(2+)$ Exchange Participates in Insulin Secretion and Glucotoxicity-Mediated Dysfunction of beta-Cells. Diabetes (2019) 68:1778-94. doi: 10.2337/db18-1112

34. Cardozo AK, Ortis F, Storling J, Feng YM, Rasschaert J, Tonnesen M, et al. Cytokines downregulate the sarcoendoplasmic reticulum pump Ca2+ ATPase $2 \mathrm{~b}$ and deplete endoplasmic reticulum $\mathrm{Ca} 2+$, leading to induction of endoplasmic reticulum stress in pancreatic beta-cells. Diabetes (2005) 54:452-61. doi: 10.2337/diabetes.54.2.452

35. Giorgi C, Baldassari F, Bononi A, Bonora M, De Marchi E, Marchi S, et al. Mitochondrial $\mathrm{Ca}(2+)$ and apoptosis. Cell Calcium (2012) 52:36-43. doi: 10.1016/j.ceca.2012.02.008

36. Bravo-Sagua R, Parra V, Lopez-Crisosto C, Diaz P, Quest AF, Lavandero S. Calcium Transport and Signaling in Mitochondria. Compr Physiol (2017) 7:623-34. doi: 10.1002/cphy.c160013

37. Bahar E, Kim H, Yoon H. ER Stress-Mediated Signaling: Action Potential and Ca (2+) as Key Players. Int J Mol Sci (2016) 17:1-22. doi: 10.3390/ijms17091558

38. Szegezdi E, Logue SE, Gorman AM, Samali A. Mediators of endoplasmic reticulum stress-induced apoptosis. EMBO Rep (2006) 7:880-5. doi: 10.1038/ sj.embor.7400779

39. He J, Carroll J, Ding S, Fearnley IM, Walker JE. Permeability transition in human mitochondria persists in the absence of peripheral stalk subunits of ATP synthase. Proc Natl Acad Sci USA (2017) 114:9086-91. doi: 10.1073/ pnas. 1711201114

40. Malhotra JD, Kaufman RJ. ER stress and its functional link to mitochondria: role in cell survival and death. Cold Spring Harb Perspect Biol (2011) 3: a004424. doi: 10.1101/cshperspect.a004424

41. Wu J, Ruas JL, Estall JL, Rasbach KA, Choi JH, Ye L, et al. The unfolded protein response mediates adaptation to exercise in skeletal muscle through a PGC-1alpha/ATF6alpha complex. Cell Metab (2011) 13:160-9. doi: 10.1016/j.cmet.2011.01.003

42. Misra J, Kim DK, Choi W, Koo SH, Lee CH, Back SH, et al. Transcriptional cross talk between orphan nuclear receptor ERRgamma and transmembrane transcription factor ATF6alpha coordinates endoplasmic reticulum stress response. Nucleic Acids Res (2013) 41:6960-74. doi: 10.1093/nar/gkt429
43. Verfaillie T, Rubio N, Garg AD, Bultynck G, Rizzuto R, Decuypere JP, et al. PERK is required at the ER-mitochondrial contact sites to convey apoptosis after ROS-based ER stress. Cell Death Differ (2012) 19:1880-91. doi: 10.1038/cdd.2012.74

44. Bouman L, Schlierf A, Lutz AK, Shan J, Deinlein A, Kast J, et al. Parkin is transcriptionally regulated by ATF4: evidence for an interconnection between mitochondrial stress and ER stress. Cell Death Differ (2011) 18:769-82. doi: $10.1038 / \mathrm{cdd} .2010 .142$

45. Cali T, Ottolini D, Negro A, Brini M. Enhanced parkin levels favor ER-mitochondria crosstalk and guarantee $\mathrm{Ca}(2+)$ transfer to sustain cell bioenergetics. Biochim Biophys Acta (2013) 1832:495-508. doi: 10.1016/j.bbadis.2013.01.004

46. Chen W, Yuan C, Lu Y, Zhu Q, Ma X, Xiao W, et al. Tanshinone IIA Protects against Acute Pancreatitis in Mice by Inhibiting Oxidative Stress via the Nrf2/ROS Pathway. Oxid Med Cell Longev (2020) 2020:5390482. doi: $10.1155 / 2020 / 5390482$

47. Sarcinelli C, Dragic H, Piecyk M, Barbet V, Duret C, Barthelaix A, et al. ATF4-Dependent NRF2 Transcriptional Regulation Promotes Antioxidant Protection during Endoplasmic Reticulum Stress. Cancers (Basel) (2020) 12:1-13. doi: 10.3390/cancers12030569

48. Yagishita Y, Fukutomi T, Sugawara A, Kawamura H, Takahashi T, Pi J, et al. Nrf2 protects pancreatic beta-cells from oxidative and nitrosative stress in diabetic model mice. Diabetes (2014) 63:605-18. doi: 10.2337/db13-0909

49. Kasai S, Yamazaki H, Tanji K, Engler MJ, Matsumiya T, Itoh K. Role of the ISR-ATF4 pathway and its cross talk with Nrf2 in mitochondrial quality control. J Clin Biochem Nutr (2019) 64:1-12. doi: 10.3164/jcbn.18-37

50. Frank M, Duvezin-Caubet S, Koob S, Occhipinti A, Jagasia R, Petcherski A, et al. Mitophagy is triggered by mild oxidative stress in a mitochondrial fission dependent manner. Biochim Biophys Acta (2012) 1823:2297-310. doi: 10.1016/j.bbamcr.2012.08.007

51. Park KS, Wiederkehr A, Kirkpatrick C, Mattenberger Y, Martinou JC, Marchetti $\mathrm{P}$, et al. Selective actions of mitochondrial fission/fusion genes on metabolism-secretion coupling in insulin-releasing cells. J Biol Chem (2008) 283:33347-56. doi: 10.1074/jbc.M806251200

52. Men X, Wang H, Li M, Cai H, Xu S, Zhang W, et al. Dynamin-related protein 1 mediates high glucose induced pancreatic beta cell apoptosis. Int $J$ Biochem Cell Biol (2009) 41:879-90. doi: 10.1016/j.biocel.2008.08.031

53. Hoppins S, Nunnari J. Cell Biology. Mitochondrial dynamics and apoptosisthe ER connection. Science (2012) 337:1052-4. doi: 10.1126/science.1224709

54. Reinhardt F, Schultz J, Waterstradt R, Baltrusch S. Drp1 guarding of the mitochondrial network is important for glucose-stimulated insulin secretion in pancreatic beta cells. Biochem Biophys Res Commun (2016) 474:646-51. doi: $10.1016 /$ j.bbrc.2016.04.142

55. Close AF, Dadheech N, Villela BS, Rouillard C, Buteau J. The orphan nuclear receptor Nor1/Nr4a3 is a negative regulator of beta-cell mass. J Biol Chem (2019) 294:4889-97. doi: 10.1074/jbc.RA118.005135

56. Close AF, Dadheech N, Lemieux H, Wang Q, Buteau J. Disruption of BetaCell Mitochondrial Networks by the Orphan Nuclear Receptor Nor1/Nr4a3. Cells (2020) 9:1-15. doi: 10.3390/cells9010168

57. Schultz J, Waterstradt R, Kantowski T, Rickmann A, Reinhardt F, Sharoyko $\mathrm{V}$, et al. Precise expression of Fis1 is important for glucose responsiveness of beta cells. J Endocrinol (2016) 230:81-91. doi: 10.1530/JOE-16-0111

58. Molina AJ, Wikstrom JD, Stiles L, Las G, Mohamed H, Elorza A, et al. Mitochondrial networking protects beta-cells from nutrient-induced apoptosis. Diabetes (2009) 58:2303-15. doi: 10.2337/db07-1781

59. Arnoult D, Soares F, Tattoli I, Girardin SE. Mitochondria in innate immunity. EMBO Rep (2011) 12:901-10. doi: 10.1038/embor.2011.157

60. Banoth B, Cassel SL. Mitochondria in innate immune signaling. Transl Res (2018) 202:52-68. doi: 10.1016/j.trsl.2018.07.014

61. Melber A, Haynes CM. UPR(mt) regulation and output: a stress response mediated by mitochondrial-nuclear communication. Cell Res (2018) 28:28195. doi: $10.1038 / \mathrm{cr} .2018 .16$

62. Abulafia-Lapid R, Gillis D, Yosef O, Atlan H, Cohen IR. T cells and autoantibodies to human HSP70 in type 1 diabetes in children. J Autoimmun (2003) 20:313-21. doi: 10.1016/S0896-8411(03)00038-6

63. Moin ASM, Nandakumar M, Diane A, Dehbi M, Butler AE. The Role of Heat Shock Proteins in Type 1 Diabetes. Front Immunol (2021) 11:612584. doi: 10.3389/fimmu.2020.612584

64. McArthur K, Whitehead LW, Heddleston JM, Li L, Padman BS, Oorschot V, et al. BAK/BAX macropores facilitate mitochondrial herniation and mtDNA 
efflux during apoptosis. Science (2018) 359:1-12. doi: 10.1126/ science.aao6047

65. Riley JS, Tait SW. Mitochondrial DNA in inflammation and immunity. EMBO Rep (2020) 21:e49799. doi: 10.15252/embr.201949799

66. Yang Y, Wang H, Kouadir M, Song H, Shi F. Recent advances in the mechanisms of NLRP3 inflammasome activation and its inhibitors. Cell Death Dis (2019) 10:128. doi: 10.1038/s41419-019-1413-8

67. Ghiasi SM, Dahllof MS, Osmai Y, Osmai M, Jakobsen KK, Aivazidis A, et al. Regulation of the beta-cell inflammasome and contribution to stressinduced cellular dysfunction and apoptosis. Mol Cell Endocrinol (2018) 478:106-14. doi: 10.1016/j.mce.2018.08.001

68. Perry AK, Chow EK, Goodnough JB, Yeh WC, Cheng G. Differential requirement for TANK-binding kinase-1 in type I interferon responses to toll-like receptor activation and viral infection. J Exp Med (2004) 199:16518. doi: 10.1084/jem.20040528

69. Anquetil F, Sabouri S, Thivolet C, Rodriguez-Calvo T, Zapardiel-Gonzalo J, Amirian N, et al. Alpha cells, the main source of IL-1beta in human pancreas. J Autoimmun (2017) 81:68-73. doi: 10.1016/j.jaut.2017.03.006

70. Negi S, Jetha A, Aikin R, Hasilo C, Sladek R, Paraskevas S. Analysis of betacell gene expression reveals inflammatory signaling and evidence of dedifferentiation following human islet isolation and culture. PloS One (2012) 7:e30415. doi: 10.1371/journal.pone.0030415

71. Reddy S, Krogvold L, Martin C, Holland R, Choi J, Woo H, et al. Distribution of IL-1beta immunoreactive cells in pancreatic biopsies from living volunteers with new-onset type 1 diabetes: comparison with donors without diabetes and with longer duration of disease. Diabetologia (2018) 61:1362-73. doi: 10.1007/s00125-018-4600-8

72. Schulte BM, Lanke KH, Piganelli JD, Kers-Rebel ED, Bottino R, Trucco M, et al. Cytokine and chemokine production by human pancreatic islets upon enterovirus infection. Diabetes (2012) 61:2030-6. doi: 10.2337/db11-1547

73. Westwell-Roper CY, Ehses JA, Verchere CB. Resident macrophages mediate islet amyloid polypeptide-induced islet IL-1beta production and beta-cell dysfunction. Diabetes (2014) 63:1698-711. doi: 10.2337/db13-0863

74. Boni-Schnetzler M, Meier DT. Islet inflammation in type 2 diabetes. Semin Immunopathol (2019) 41:501-13. doi: 10.1007/s00281-019-00745-4

75. Ferreira RC, Guo H, Coulson RM, Smyth DJ, Pekalski ML, Burren OS, et al. A type I interferon transcriptional signature precedes autoimmunity in children genetically at risk for type 1 diabetes. Diabetes (2014) 63:253850. doi: $10.2337 / \mathrm{db} 13-1777$

76. Szymczak F, Colli ML, Mamula MJ, Evans-Molina C, Eizirik DL. Gene expression signatures of target tissues in type 1 diabetes, lupus erythematosus, multiple sclerosis, and rheumatoid arthritis. Sci Adv (2021) 7:1-11. doi: 10.1126/sciadv.abd7600

77. Kim J, Gupta R, Blanco LP, Yang S, Shteinfer-Kuzmine A, Wang K, et al. VDAC oligomers form mitochondrial pores to release mtDNA fragments and promote lupus-like disease. Science (2019) 366:1531-6. doi: 10.1126/ science.aav 4011

78. Chen J, Gusdon AM, Piganelli J, Leiter EH, Mathews CE. mt-Nd2(a) Modifies resistance against autoimmune type 1 diabetes in NOD mice at the level of the pancreatic beta-cell. Diabetes (2011) 60:355-9. doi: 10.2337/db10-1241

79. Lightfoot YL, Chen J, Mathews CE. Role of the mitochondria in immunemediated apoptotic death of the human pancreatic beta cell line betaLox 5 . PloS One (2011) 6:e20617. doi: 10.1371/journal.pone.0020617

80. Chin KV, Cade C, Brostrom CO, Galuska EM, Brostrom MA. Calciumdependent regulation of protein synthesis at translational initiation in eukaryotic cells. J Biol Chem (1987) 262:16509-14. doi: 10.1016/S00219258(18)49285-X

81. Krebs J. The influence of calcium signaling on the regulation of alternative splicing. Biochim Biophys Acta (2009) 1793:979-84. doi: 10.1016/ j.bbamcr.2008.12.006

82. Mukherjee R, Das A, Chakrabarti S, Chakrabarti O. Calcium dependent regulation of protein ubiquitination - Interplay between E3 ligases and calcium binding proteins. Biochim Biophys Acta Mol Cell Res (2017) 1864:1227-35. doi: 10.1016/j.bbamcr.2017.03.001

83. McLaughlin RJ, de Haan A, Zaldumbide A, de Koning EJ, de Ru AH, van Veelen PA, et al. Human islets and dendritic cells generate posttranslationally modified islet autoantigens. Clin Exp Immunol (2016) 185:133-40. doi: 10.1111/cei.12775
84. Rondas D, Crevecoeur I, D’Hertog W, Ferreira GB, Staes A, Garg AD, et al. Citrullinated glucose-regulated protein 78 is an autoantigen in type 1 diabetes. Diabetes (2015) 64:573-86. doi: 10.2337/db14-0621

85. Luciani A, Villella VR, Vasaturo A, Giardino I, Pettoello-Mantovani M, Guido S, et al. Lysosomal accumulation of gliadin p31-43 peptide induces oxidative stress and tissue transglutaminase-mediated PPARgamma downregulation in intestinal epithelial cells and coeliac mucosa. Gut (2010) 59:311-9. doi: 10.1136/gut.2009.183608

86. Tatsiy O, McDonald PP. Physiological Stimuli Induce PAD4-Dependent, ROS-Independent NETosis, With Early and Late Events Controlled by Discrete Signaling Pathways. Front Immunol (2018) 9:2036. doi: 10.3389/ fimmu.2018.02036

87. van Lummel M, Duinkerken G, van Veelen PA, de Ru A, Cordfunke R, Zaldumbide A, et al. Posttranslational modification of HLA-DQ binding islet autoantigens in type 1 diabetes. Diabetes (2014) 63:237-47. doi: $10.2337 / \mathrm{db} 12-1214$

88. Trinanes J, Ten Dijke P, Groen N, Hanegraaf M, Porrini E, RodriguezRodriguez AE, et al. Tacrolimus-Induced BMP/SMAD Signaling Associates With Metabolic Stress-Activated FOXO1 to Trigger beta-Cell Failure. Diabetes (2020) 69:193-204. doi: 10.2337/db19-0828

89. Kolic J, Beet L, Overby P, Cen HH, Panzhinskiy E, Ure DR, et al. Differential Effects of Voclosporin and Tacrolimus on Insulin Secretion From Human Islets. Endocrinology (2020) 161:1-14. doi: 10.1210/endocr/bqaa162

90. Unanue ER, Ferris ST, Carrero JA. The role of islet antigen presenting cells and the presentation of insulin in the initiation of autoimmune diabetes in the NOD mouse. Immunol Rev (2016) 272:183-201. doi: 10.1111/imr.12430

91. Chandra V, Karamitri A, Richards P, Cormier F, Ramond C, Jockers R, et al. Extracellular acidification stimulates GPR68 mediated IL-8 production in human pancreatic beta cells. Sci Rep (2016) 6:25765. doi: 10.1038/srep25765

92. Wiley CD, Velarde MC, Lecot P, Liu S, Sarnoski EA, Freund A, et al. Mitochondrial Dysfunction Induces Senescence with a Distinct Secretory Phenotype. Cell Metab (2016) 23:303-14. doi: 10.1016/j.cmet.2015.11.011

93. Aguayo-Mazzucato C. Functional changes in beta cells during ageing and senescence. Diabetologia (2020) 63:2022-9. doi: 10.1007/s00125-020-05185-6

94. Moltedo O, Remondelli P, Amodio G. The Mitochondria-Endoplasmic Reticulum Contacts and Their Critical Role in Aging and Age-Associated Diseases. Front Cell Dev Biol (2019) 7:172. doi: 10.3389/fcell.2019.00172

95. Thompson PJ, Shah A, Ntranos V, Van Gool F, Atkinson M, Bhushan A. Targeted Elimination of Senescent Beta Cells Prevents Type 1 Diabetes. Cell Metab (2019) 29:1045-60.e10. doi: 10.1016/j.cmet.2019.01.021

96. Li N, Liu F, Yang P, Xiong F, Yu Q, Li J, et al. Aging and stress induced beta cell senescence and its implication in diabetes development. Aging (Albany NY) (2019) 11:9947-59. doi: 10.18632/aging.102432

97. Aguayo-Mazzucato C, Andle J, Lee TB Jr, Midha A, Talemal L, Chipashvili V, et al. Acceleration of beta Cell Aging Determines Diabetes and Senolysis Improves Disease Outcomes. Cell Metab (2019) 30:129-42 e4. doi: 10.1016/ j.cmet.2019.05.006

98. Merry TL, Chan A, Woodhead JST, Reynolds JC, Kumagai H, Kim SJ, et al. Mitochondrial-derived peptides in energy metabolism. Am J Physiol Endocrinol Metab (2020) 319:E659-66. doi: 10.1152/ajpendo.00249.2020

99. Kim SJ, Xiao J, Wan J, Cohen P, Yen K. Mitochondrially derived peptides as novel regulators of metabolism. J Physiol (2017) 595:6613-21. doi: 10.1113/JP274472

100. Eizirik DL, Pasquali L, Cnop M. Pancreatic beta-cells in type 1 and type 2 diabetes mellitus: different pathways to failure. Nat Rev Endocrinol (2020) 16:349-62. doi: 10.1038/s41574-020-0355-7

101. Ellingsgaard H, Hauselmann I, Schuler B, Habib AM, Baggio LL, Meier DT, et al. Interleukin-6 enhances insulin secretion by increasing glucagon-like peptide-1 secretion from L cells and alpha cells. Nat Med (2011) 17:1481-9. doi: $10.1038 / \mathrm{nm} .2513$

102. Zhou T, Hu Z, Yang S, Sun L, Yu Z, Wang G. Role of Adaptive and Innate Immunity in Type 2 Diabetes Mellitus. J Diabetes Res (2018) 2018:7457269. doi: $10.1155 / 2018 / 7457269$

103. Beery ML, Jacobsen LM, Atkinson MA, Butler AE, Campbell-Thompson M. Islet amyloidosis in a child with type 1 diabetes. Islets (2019) 11:44-9. doi: 10.1080/19382014.2019.1599707

104. Westermark GT, Krogvold L, Dahl-Jorgensen K, Ludvigsson J. Islet amyloid in recent-onset type 1 diabetes-the DiViD study. Ups J Med Sci (2017) 122:201-3. doi: 10.1080/03009734.2017.1359219 
105. Batandier C, Guigas B, Detaille D, El-Mir MY, Fontaine E, Rigoulet M, et al. The ROS production induced by a reverse-electron flux at respiratory-chain complex 1 is hampered by metformin. J Bioenerg Biomembr (2006) 38:33-42. doi: 10.1007/s10863-006-9003-8

106. Detaille D, Guigas B, Chauvin C, Batandier C, Fontaine E, Wiernsperger N, et al. Metformin prevents high-glucose-induced endothelial cell death through a mitochondrial permeability transition-dependent process. Diabetes (2005) 54:2179-87. doi: 10.2337/diabetes.54.7.2179

107. Guigas B, Detaille D, Chauvin C, Batandier C, De Oliveira F, Fontaine E, et al. Metformin inhibits mitochondrial permeability transition and cell death: a pharmacological in vitro study. Biochem J (2004) 382:877-84. doi: 10.1042/BJ20040885

108. Vial G, Detaille D, Guigas B. Role of Mitochondria in the Mechanism(s) of Action of Metformin. Front Endocrinol (Lausanne) (2019) 10:294. doi: 10.3389/fendo.2019.00294

109. Kondo M, Tanabe K, Amo-Shiinoki K, Hatanaka M, Morii T, Takahashi H, et al. Activation of GLP-1 receptor signalling alleviates cellular stresses and improves beta cell function in a mouse model of Wolfram syndrome. Diabetologia (2018) 61:2189-201. doi: 10.1007/s00125-018-4679-y

110. Yusta B, Baggio LL, Estall JL, Koehler JA, Holland DP, Li H, et al. GLP-1 receptor activation improves beta cell function and survival following induction of endoplasmic reticulum stress. Cell Metab (2006) 4:391-406. doi: $10.1016 /$ j.cmet.2006.10.001
111. Fattah H, Vallon V. The Potential Role of SGLT2 Inhibitors in the Treatment of Type 1 Diabetes Mellitus. Drugs (2018) 78:717-26. doi: 10.1007/s40265018-0901-y

112. Asahara SI, Ogawa W. SGLT2 inhibitors and protection against pancreatic beta cell failure. Diabetol Int (2019) 10:1-2. doi: 10.1007/s13340-018-0374-y

113. Ovalle F, Grimes T, Xu G, Patel AJ, Grayson TB, Thielen LA, et al. Verapamil and beta cell function in adults with recent-onset type 1 diabetes. Nat Med (2018) 24:1108-12. doi: 10.1038/s41591-018-0089-4

114. Xu G, Chen J, Jing G, Shalev A. Preventing beta-cell loss and diabetes with calcium channel blockers. Diabetes (2012) 61:848-56. doi: 10.2337/ db11-0955

Conflict of Interest: The authors declare that the research was conducted in the absence of any commercial or financial relationships that could be construed as a potential conflict of interest.

Copyright (c) 2021 Vig, Lambooij, Zaldumbide and Guigas. This is an open-access article distributed under the terms of the Creative Commons Attribution License (CC BY). The use, distribution or reproduction in other forums is permitted, provided the original author(s) and the copyright owner(s) are credited and that the original publication in this journal is cited, in accordance with accepted academic practice. No use, distribution or reproduction is permitted which does not comply with these terms. 